\title{
BIJURAGEN TOT DE SPRAAKKUNST VAN HET OUDJAVAANSCH
}

\section{Het suffix akĕn.}

Dit suffix, dat in sommige talen als afzonderlijk voorzetsel bewaard is en dus in verbinding met een stamwoord werkwoorden vormt die met onze samengestelde werkwoorden te vergelijken zijn, drukt zekere betrekkingen uit, welke in onze taal worden uitgedrukt door 'met", voorts door "tot, voor, ten behoeve van; aangaande, ten opzichte van, ten onderwerp hebbende". Wordt zulk een samengesteld wkw. verbonden met een voorvoegsel dat alleen bij een transitief begrip, althans oorspronkelijk optreedt, dan krijgt zoo'n werkwoord de beteekenis van een causatief, welke beteekenis het behouden kan zelfs als het voorvoegsel wegvalt, bijv. in 't passief. Ter verduidelijking van 't gezegde mogen hier eenige voorbeelden volgen.

Bij werkwoorden als "gaan, komen, loopen, vluchten, vliegen" en dgl. geeft akĕn te kennen "met". Dus palaywakĕn, wegvluchten met ${ }^{1}$, van palayu, vluchten; wörakĕn, wegvliegen met, van wör. vliegen; tĕmwakĕn, samenkomen met, een ontmoeting hebben met, stuiten op, van tĕmu, samenkomst.

Ligt in 't grondwoord het begrip van een handeling die men met behulp van zeker instrument of ander voorwerp verricht, ook dan duidt akĕn een "met" aan. Bijv. panahakěn hro, met een pijl schieten; pupuhakĕn gadâ, met een knots beuken; panggutukakĕn, met iets gooien. Nu gaat een begrip als "schieten met" van zelf over in den zin van "gebruiken om te schieten"; "beuken met", in dat van "bezigen om te beuken". Bij woorden als "gooien, werpen" e. dgl. staat in onze taal het voorwerp waarmeê de handeling geschiedt in den accusatief, doch in 't Ojav. in

${ }^{1}$ De Oudj. vormen geef ik in den imperatief, de Hollandsche vertaling in den infinitief. De zinnen waar de voorbeelden voorkomen en de plaatsen zullen in 't vervolg meêgedeeld worden. 
den instrumentalis; wij zeggen "ik werp een steen", al kunnen wij ook zeggen "ik werp met een steen"; in 't Ojav. is alleen deze laatste constructie gebruikelijk, terwijl als onmiddellijk voorwerp der handeling beschouwd wordt de persoon of zaak die men wil treffen; dus in plaats van "ik werp een steen op hem", zegt men in 't Ojav. "ik werp hem met een steen". In veel gevallen laat onze taal het gebruik van "met" niet toe, al wordt het voorwerp genoemd met behulp waarvan de handeling geschiedt; bijv. a yata kĕn hrû, een pijl aanleggen, hoewel het instrumentaal-begrip duidelijk genoeg uitkomt, vooral als men vergelijkt mangay at câpa, den boog spannende. Tihangakĕn hrû, den pijl opleggen, zou men des noods kunnen vertalen "met den pijl voorzien", doch dit is eenigszins gedwongen. Hudanakĕn puṣpa is "regenen met bloemen", hetgeen van zelf overgaat in den zin van "bloemen laten regenen, een regen van bloemen laten vallen"; terwijl hinudanan warâstra is "met voortreffelijke schichten beregend, met een regen van schichten overstelpt."

Uit een begrip als wehakĕn, "als gift gebruiken, tot gift of gave doen dienen", terwijl aweh, maweh beteekent "geven, afstaan", ontwikkelt zich dat van "als bewijs van mildheid of vroomheid schenken, weggeven". bijv. a mehakĕn u dakâñjali, "als offer voor den doode een handvol water plengende." A mĕng y a$\mathrm{k}$ ĕn laku is "den nacht gebruikende tot den tocht, den tocht 's nachts ondernemende."

Zeer gewoon is de beteekenis van "tot, voor, ten behoeve van", die in akĕn opgesloten ligt. Bijv. a stwakĕn, "goedkeuring schenken tot, op; zegen geven op", en ook "gelukwenschen voor", van a stu, het zij zoo! Iring a ěn i, tot geleide zijn voor iemand, z. v. a. iemand vergezellen. A n u ntunakĕn, tot geleide zijnde voor iemand. Sumarathyak ĕn, hij trad op als wagenmenner voor - . A m rihakĕn, zijn best doende ten behoeve van, zich beijverende voor - H u merakĕn, hij wachtte tot. Tan-antyakĕn, hij wachtte niet tot, wachtte niet af. Munagyakĕn i haywa, hij uitte wenschen voor - A ngrahinakĕn, den dag afwachtende, tot den morgen toe (wakende).

Meermalen beantwoordt akĕn aan ons "omtrent, over, naar." W arahakĕn, meedeeling doen omtrent iets, iets melden. Majarakĕn, hij gaf inlichting omtrent iets. 'Ta ñâkĕn, vragen omtrent, naar iets. An angisakĕn, weenende over iets. Tan kasangçayâkĕna kan vertaald worden met "ten opzichte, dienaangaande 
mag niet geaarzeld worden", maar ook "daarmee m.n.g. worden."

Wanneer begrippen als "zeggen, bevelen, leeren, vermanen, zingen" en dgl. ak ĕn aannemen, dan is het onmiddellijk voorwerp steeds datgene wat geuit wordt, terwijl de niet-samengestelde vorm tot onmiddellijk voorwerp een persoon heeft. Zoo heeft bijv. k u m o n (hij) beveelt , beval, in afwijking van ons taaleigen, maar in overeenstemming met het Latijn, tot voorwerp den persoon tot wien het bevel gericht wordt; dus Kṛṣna kumon Arjuna, K. jussit Arjunam" 1; maar kumonakĕn is "beveelt iets" of "verordent ten opzichte van" terwijl het onderwerp meestal de persoon is die het bevel overbrengt, niet degene van wien 't bevel uitgaat. Is het eenvoudige $\mathrm{kkw}$. intransitief, zooals humatur, makt zijn opwachting, ook dan beteekent de samenstelling manghaturakĕn, "iets aanbiedende", manghaturi . "het hem aanbiedende", zoodat in den vorm met $i$ het begrip ligt van manghaturakĕn + het suffix $\mathrm{i}=\mathrm{an}$. Winarah $\mathrm{i}$ is "verwittigd van, onderwezen in"; warahakĕnta ri Pânḍuputra, het worde door u medegedeeld aan de Pâṇawa's"; winarahakĕna, het zal medegedeeld worden.

Dewijl kumonakĕn beteekent "geeft bevel tot," zooals bijv. BY, 2, 3, kan men het als een voorbeeld aanhalen dat in a k ĕn "t begrip ligt van "tot"; zelfs waar 't onderwerp der handeling een bode of degene is die het bevel overbrengt, kan men de beteekenis beschouwen als een uitbreiding van de vorige; de hoofdzaak is, dat het onmiddellijk voorwerp een zaak is, en in zooverre nadert het de opvatting waarbij a k ĕn wijst op het middel waarmeê de handeling tot stand wordt gebracht.

Uit tina ñâkĕn, waaromtrent of waarnaar gevraagd wordt, blijkt hoe in bepaalde gevallen de begrippen "omtrent" en "naar" elkaar raken. Begrijpelijk is dus hoe manuduhakĕn kan beteekenen "wijzzende naar, aanwijzende"; angawuryakĕn, den rug toekeerende naar of ten opzichte van; angharĕpakĕn, de voorzijde toekeerende naar, vóór zich hebbende; pir ěngwakĕna, worde geluisterd naar.

Verder worden met a k ĕn tweeërlei soort van causatieven gevormd. Dezulke, waarbij akĕn verbonden wordt met een naamwoord, vooral deelwoordachtige adjectieven, geven in 't algemeen te kennen

1 Ook kumon $\mathrm{ri}$ is niet ongewoon, maar dit is te verklaren als een gevolg daarvan dat de accusatief vaak door den datief wordt uitgedrukt.

7e Volgr. I. 
"maken dat iemand of iets ondergaat, in zekere gesteldheid komt." Bijv. dinohakĕn, wordt verwijderd, van doh, afstand; numanâkĕn, (hij) verwoestte, van nanâ, verwoest; huıilangakĕn, vernietigt, doet te niet, ruimt uit den weg, doet verdwijnen, van hilang, vernietigd, verdwenen, weg; çumîrṇnạkĕna, hij zal verdelgen, van çîrṇna, verdelgd. Gewoonlijk beantwoorden aan deze en soortgelijke woorden in onze taal samenstellingen met $\mathrm{ver}^{1}$. Werkwoorden van deze soort zou men kunnen brengen tot de klasse van "facere fieri." Wordt a kĕn verbonden met werkwoordstammen, onverschillig of ze op zich zelf transitief of intransitief zijn, mits ze een handeling aanduiden, dan ontstaan causatieven in engeren zin. Bijv. m a ng dĕm a kĕn g a ja, de olifanten doende aanvallen ${ }^{1}$, van mangdĕ ı ak, aanvallende; angrapak ěn açwa, de paarden doen renuen, tot rennen aanzetten, van krap, wedren; mamulihakĕn, doen terugkeeren tot den strijd, den strijd laten hervatten van pulih, hervatting; tan pangdadyakĕna, het mag niet veroorzaken, doen ontstaan, van dadi, worden; a manghuripakĕn, in leven doen blijven; maken dat (een geslacht) in stand blijft," en ook "doen herleven", van panghurip, middel om te leven. Vorınelijk zijn de stammen ook van deze causatieven naamwoorden, maar in verband met het suffix schijnen ze de waarde te hebben van eenvoudige werkwoorden.

Met eenig recht zou men werkwoorden als mulihak ĕn (passief inulihakĕn) naar huis terugbrengen, eigenlijk "naar huis teruggaan met iemand" tot de klasse der causatieven kunnen brengen. Immers "iemand naar huis terugbrengen" komt feitelijk nagenoeg overeen met "maken dat iemand naar huis terugkeert", maar toch voelt men dat mulihakĕn van mulih geen causatief in engeren zin is, zooals ma mulihakĕn, laten terugkeeren, den strijd doen hervatten, van pulih. Met wörakĕn, wegvliegen met, en dgl. verbindt zich de voorstelling van "door weg te vliegen redden," maar dit wordt niet onmiddellijk door den vorm uitgedrukt. De moeielijkheid om de verschillende beteekenissen der werkwoorden op a k ĕn te klassificeeren, moge als bewijs gelden voor den nauwen samenhang tusschen die beteekenissen.

In sommige gevallen makt het spraakgebruik tusschen 't eenvoudige werkwoord en 't samengestelde slechts een gering onderscheid.

1 Behalve wanneer ver eene verandering aanduidt.

2 Hierin ligt evenzeer 't begrip van "met de olianten aanvallen". 
Bijv. a ngiring is "vergezellen, begeleiden", vooral ter staatsie; angiringakĕn en miringakĕn is "geleiden, een geleide vormen voor (iemand)". Van den stam tinggal komt o. a. (m) atinggal, verlaten, alleen laten, waarbij als verbaalsubstantief behoort patinggal, 't verlaten, weggaan van (ri, eene plaats); 't verscheiden, overlijden; 't achterwege blijven; doch paninggal, verb.subst. van (m)aninggal, is ook "t verlaten (met opzet), vertrek, afscheid"; tuminggal i of ri, hij verliet (bijv. zijne vrouw); tuming galakĕn is "verlaten, aan zijn lot overlaten (van een wicht door de ouders); laten varen, afstand doen van"; doch ook "maken dat achterwege blijft".

Het verdient bijzonder opgemerkt te worden dat menig wkw. op akĕn het prefix pa vertoont. Bijv. sira ta pinatapâkĕn, voor hem nu wordt tapas uitgeoefend, AW. 6, 4. Zoo ook pin a g a w a y a kĕn, voor wien gemaakt (verordend) werd, Âdip. 153; waarvoor gemaakt was, z. v. a. voorzien van; lawang nikang guhâ pinagawayakẹ̆n jantra cakra, ald. 40. Pinaguñĕpguñ ĕpakĕn, waarover veel gepraat werd, z. v. a. werd het onderwerp der gesprekken, AW. 15, 3. P a damĕlakna, worde ten uitvoer gelegd, KO. Pinarabyakĕn, tot echtgenoote genomen $\mathrm{AW}$. 28, 7. Pinasotaken, op wien 't verlangen gericht is, naar wien verlangd wordt, z. v. a. beminde; tĕka sira sang pinasotakĕn ing twas, hij kwam, de zielsbeminde, Smarad. f 35 ; in 't Skr. zou men zeggen prârthita.

Deze vormen met voorvoegsel pa herinneren aan de Bataksche werkwoorden op kon (spr. hon) Tobasch, kĕn Dairisch, en voorvoegsel pa. Bijv. papandehon, iemand tot werkman maken, laat zich vergelijken met parabyakĕn; het verschil is dat in 't passief het achtervoegsel hon wegvalt, wat in 't Ojav. niet geschiedt. ${ }^{1}$ Behalve 't voorvoegsel pa vindt men ook soms pang; bijv. pinangrakĕtakĕn, voor wien een dans of pantomime uitgevoerd wordt, Âdip 150. Ook deze vorm heeft ziju tegenhanger in 't Bataksch; bijv. hu-pangolihon djolo riyar-nami on, dat door mij deze onze spaansche matten ter kooping van een vrouw gebezigd worden; unang ang go pandekdekkon, laat het toch niet telkens naar beneden vallen; di-pambuwatkon, door hem wordt ten behoeve van (dien persoon) genomen. ${ }^{1}$ In pangulihon, en andere net voorvoegsel pang, ligt een meer-

1 Zie v. d. Tuuk, Tobasche Spr. p. $129 ; 133 ; 177 ; 179$. 
voudig begrip opgesloten, hetgeen natuurlijk is, omdat pang, in tegenstelling tot $\mathrm{pa}$ bet kenmerk is van een imperfectief, dat van zelf overgaat in een duratief. Duidelijk is ook Oudj. pangrakĕtakĕn een imperfectief. Overigens blijkt dat het Bataksch bij de werkwoorden op hon, enz. pa en pang vereischt, waar het Ojav. hetzelfde uitdrukt door a k ĕn alleen, zonder voorvoegse! pa en pang. Ook het hedendaagsche Javaansch bezit werkwoorden op a k ĕn, a ke met voorvoegsels pa (actief ma), bijv. pa d a m ĕlakĕn, pagawekake, doch een vaste regel voor dit spraakgebruik is nog niet gevonden.

De nu volgende voorbeelden strekken tot nadere toelichting van 't boven verhandelde. Lĕbuh nikang pura kinonakĕn bhôșan an, er werd bevel gegeven dat het tournooiveld van den kraton zou versierd worden, BY. 2, 4; ajũâ Çrî Mahârâja kumonakĕn ikang wanwe Kudadu, 't bevel van Z. Maj. den Koning verordent omtrent het dorp Kudadu, KO. Inastwakĕn ujar Mahâsurapati, de rede van den grooten Asuraheerscher werd toegejuicht, AW. 20,5 Sang hyang Surendra mastwakĕn ya ̃̃ jayeng (d. i. jayâ + ing) prang, de god Indra gaf zijn toestemming, hechtte zijn goedkeuring er aan, dat zij in den oorlog zouden overwinnen, BY. 9,2 ; mastwâkĕn pĕjaha Ja yadratha, hechtte zijn zegel er aan, gaf zijn fiat er op, dat Jayadratha zou sneuvelen; angastwakĕn ri, toestemming gevende tot, goedkeurende, Âdip. 17, a; kâla Droṇa 'n in astwakĕn, ten tijde dat Droṇa in zijn waardigheid bevestigd, ingezegend werd, BY. 13, 12; Âdip. 109. M unagyakĕn i haywa sang prabhu, zij uitten zegenwenschen voor 't heil van den vorst, 2, 2. Aprrgi 'n humîrakĕn i ken-ya sâk ring hĕnu, haastig sleepten zij de rokken op die op weg afgezakt waren, 2, 10. Manuduhakĕn ry y ungwana nira, zij wezen de plaatsen aan waar zij zouden zitten, 7, 2. Mintonakĕn krama nira 'n tuhu Wișṇumûtti, hij toonde hoe hij in waarheid een belichaming was van Wiṣnu , 8, 1. Ngkâ lumrâng puṣpawarṣeng ghana sinaw u rakĕn sang watěk Siddhasang gha, toen verspreidde zich een regen van bloemen in de wolken, gestrooid door de scharen van Siddha's, 9, 1. T-a lap t-u lihakĕn i ka ḍatwan-ta, neem hem mede terug naar uw paleis, Âdip. 81: inalap ikang rare, in ulihakĕn ireng âçrama, hij nam den knaap met zich mede terug naar de kluizenarij, 2l; 103. N dak-wörakĕn kita, ik wil met u wegvliegen, Adip. 114; wöraken mami kita kabeh, 
ik zal metu allen wegvliegen ${ }^{1}$, 115. Iña nira y a n palaywakĕn (zó́ te l. voor $\mathrm{mala}^{\circ}$ ) i sang mạ̣ik ning ahayu, haar Dueña is het die met het juweel der schoonen gevlucht is, BK. 68. Tan d w a y arpupuhakĕn tekang gadâ bhîṣaṇa, onmiddellijk beukte hij met zijn geduchte knots, 208. Binu ñcangakĕn gulû nika, met diens hals werd gegooid, BY. 18, 8; (het lijk) binuñeangakĕn ing sukĕt, werd in 't struikgewas weggeworpen, Âdip. 64. Ginutukakĕn çirah-nya ri Suyodhana, zijn ('s reuzen) hoofd werd Suyodhana toegesmeten, BY. 18, 7; manggutukakĕn (het hoofd) i sang Korawapati, gooiende naar den heerscher der Kaurawa's, 20, 9. Lâwan tang kanin ing kapan warasa de ni sĕpah ira lanâjinampyakĕn, en hoe zou de gewonde kunnen herstellen door 't kouwsel, dat aldoor als geneesmiddel aangewend (of: beschouwd) werd? 44, 15. Angu pakṣamâkĕn i saçîla nira, zij vroegen vergiffenis voor hun gedrag, 23, 9. Sumarat (h) yakĕna kâryya sang prabhu, om als helper op te treden voor de belangen van den Vorst, BK. 122. Amarahakĕn datĕng sang Asurendra, de komst van den Asuravorst berichtende; eñjing sang nṛpaputra yarwarahakĕn tang ipyan, 's morgens, deelde de prins meê wat hij gedroomd had, 112. Toh jîwâmrihakĕn ri sang Naraka, met levensgevaar deed hij zijn best voor Naraka, 217. Mâjarakĕn hana$\mathrm{n}$ ta, hij gaf inlichting omtrent uw verblijf, 53. Ang gîtakĕn kûng ning on eng, den weedom der minnende tot onderwerp van een lied makende, in dicht brengende, 49. Tan-antyakĕn sampuna ning warah sira, hij wachtte niet totdat het bericht ten einde zou zijn, 210. Mucapakĕn çabda pratijñânira, hij sprak de woorden van zijn gelofte uit, BY. 19, 23; a ngucapakĕn w a c ana, eene rede uitsprekende, Sutas. 67, o., u m u capakĕn tatwa Bhaṭâra mwang Bhațâri, hij sprak over (z. v. a. beschreef, legde uit) het ware wezen van Bhatâra en Bhațâri, Kosm.; tan u capakĕna, om niet te spreken van, Âdip. $26 ; 86$. H u merakĕn patya ni tanghuluñ juga, zij wacht slechts op mijn dood, BK. 108. Sirângrahinakĕn (zoo te l. voor sirâro ), hij. wachtte den dag af. bleef wakker tot den morgen toe, 111. Anĕmwakĕñ cora lumampah ing kulĕm, in aanraking komende met, stuitende op, ontmoetende roovers die 's nachts rond-

1 De passief-constructie wordt, waar ons taalgebruik het vereiseht, door de actieve vervangen. 
loopen, 109. Anangisakĕn lara ning mapasah, weenende over 't leed der gescheidenen, 71. Sang nṛpâtınaja manolih amaspadakĕn, de prins keek om acht gevende, 70. Kadi megha manghudanakĕn, paḍa nira yarwĕhakĕnnikang dâna, te vergelijken met een wolk die regen geeft was hij bij 't schenken van zijne milde giften, Râm. 1, 5. Anghudanakĕn warâstra, de voortreffelijke schichten als regen doen neerkomen, BY. 16, 2; manghudanakěn warșajalada, de regenwolken lieten regen vallen, Âdip. 159. Anûtakĕn i sarasa sang hyang Âga ma, al wat in de heilige wet vervat is opvolgen (of: nakomen), doch ook an âtakĕn manah-nya durwiweka, zijn onverstandigen geest volgende, BY. 52, 3; BK. 144. H a n a pwekang cûḍ̂mani, ya tiku yogya srahakĕna, daar is namelijk nog het kroonjuweel, dat behoort uitgeleverd (of: ter uitlevering aangeboden) te worden, BY. 51, 23, doch kasrah cûdamani, het kroonjuweel werd overgegeven, 51, 29. Tanwyarthân winalĕsakĕn (nl. sañjata nira), zonder falen wreekte hij zich (z. v. a beantwoordde hij den aanval) met zijn wapen, 15, 17. Tumihangakĕn ikang çarottama, hij legde zijn uitstekende pijl op (den boog), 13, 1. Angawuryyakĕn kuṭa, den rug keerende naar de veste, met den rug staande n. d. v.,

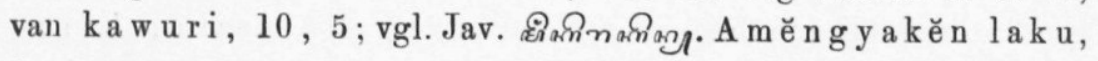
den nacht gebruiken voor den tocht (of: gedurende den nacht den tocht doen, daarvoor den nacht bestemmen), BK. 210, doch sawang jĕnu kanaka winĕng y a ǩn, gelijk goudgeel smeersel dat men een nacht over heeft laten staan, BY. 13, 1. Tĕhĕr a naw ĕng y ak ĕn, turung a t anghi, hij sliep voort den geheelen nacht door, en werd nog niet wakker, van sawĕngi, BK. 22. Hĕnĕngakĕna kamantyan sang Kṛṣna'n sĕḍ̆ng iniwö, laten we voor een poos zwijgen over Kṛṣna (al. laten we een poos K. laten rusten), terwijl hij onthaald werd, BY. 4, 4; h ĕn ĕng akĕna ng kathâ sakarĕng, laten wij een poos het verhaal laten rusten, Âdip. 29; 84; y an hĕnĕngakĕna sapolah i nghulun, indien men mij stilletjes laat begaan bij al wat ik doe, Sutas. $66, b$; zoo ook anghĕnĕngakĕn i kaka-nta, uw ouderen broeder (geliefde) stilletjes laten begaan, BK. 54; vgl. KBWdb. i. v. h ĕn ĕng. Ulah ṇ̣pati Koraweçwara'n ahöm pirĕngwâkĕna, verneem (eig. luister er naar, hoor toe) hoe de vorst der Kaurawa's raad hield, 10,1 . A s ĕmu Kâla krodhângĕntyakĕna $\mathrm{j}$ ag at, hij leek als Kâla in toorn aan de wereld een einde 
willeude maken, 12, 11. Iki nghîng antaka sinama yâkĕn $\mathrm{Paçupati,} \mathrm{dit} \mathrm{slechts} \mathrm{is} \mathrm{als} \mathrm{voorwaarde} \mathrm{(z.} \mathrm{v.} \mathrm{a.} \mathrm{oorzaak)} \mathrm{gesteld}$ voor (miju) dood 36,17 . Tanwun tikâku jumayâkĕna ri prabhu-ngku, het kan niet missen of ik zal mijnen heer de overwinning verschaffen, 35, 12. Pijĕr kângĕn de ning humilangakĕna ng çatru, uitsluitend er op bedacht om den vzand te vernietigen, 36,10 . Matangnya sira pintakâsihana kĕdwakĕna tangisana prihĕn tĕmĕn, daarom smeek hem, beweeg hem door drang er toe, bezweer hem met tranen opdat hij trouw zij, 36, 4. Motus ri Nakula marâ-ngkâ mratyakṣakĕna phala nirâwâk, hịj zond een bode naar Nakulo om er heen te gaan en de vrucht van wat hij zeide te toonen (eig. duidelijk te maken) 36, 2. Anggyâkĕn lampah ing syandana, hij (Karṇa) verhaastte de vaart van zijn karos, 27,9 . Angunyakĕn stawa, loftuitingen doende klinken $23,9$. Lunghâng kâla gumanti tang Kaliyuga mralayâkĕn i samûha ning jagat, na verloop van tijd volgt de Kaliyuga die de gansche wereld doet ondergaan, 52, 3. Angdadyâkĕna pagĕha ning jîwa ri kita, (dat) zal maken dat u het leven verzekerd zal zijn, 51,24 ; ta pintakâsih ta ri sang kawîndra, lara-ngku dadyâkĕna gîtabhâșa, verzoek toch vriendelijk den dichtervorst dat mijn hartzeer 't onderwerp vorme van een treurzang, 44, 4. Tañjrih mangkin umangsö manglěpasakĕn çarawara kadi warṣa yantibâ, onvervaard rukte hij al voorwaarts, uitstekende pijlen afschietende als een neervallenden regen, BY. 13, 26; mangkin krodha Yudhiṣthirânglěpasakĕn çarawara, al toorniger schoot Yudhișthira uitstekende pijlen af; nimitta nira gadgadânglĕpasakĕn wuwus ahala ri pañca Pâṇa a a, daarom stiet hij (eig. liet hij los) met bewogen stem leelijke woorden tegen de vijf Pâṇ̣awa's uit, 49,4 ; lĕpas a ĕn! schiet (het wapen) af! Âdip. 39 ; ngkâ Çrî-Kṛṣna kumon ri Dharmmasuta pustaka lĕpasakĕna, toen beval Kṛ̣ṇa aan Yudhișțira het (wapen) Pustaka af te schieten (letterlijk: dat afgeschoten zou worden), 42, 5. Y ekâ hrû nira mahâçakti 'n lěpasakĕn, toén werd zijn machtige pijl afgeschoten, BK. 201: (cakra) linĕpasakĕn ira, de discus werd door hem afgeschoten (geslingerd) 28. Çrî Jayakatyĕng sakeng Glangglang, sâkṣât parângmukha (zoo te l.) 'n lumampahakĕn kṛtâlpâswakâra, Z. Maj. Jayakatong, die als een vijand lage dingen ver- 
richtte in strijd met zijn plicht, KO. (in Pararaton p. 78) Mahy un humarișṭakna Çrî-Kṛtanagara 'n hanerikang nâgare Tu mapĕl, van zins Z. Maj. Kṛtanagara, die in 't rijk van Tumapěl was, in ' $t$ ongeluk te storten, van Skr. a riṣt a, ongeluk, als adjectief opgevat; ald. Çrî Dharmmasûnûmiringakĕn i sirânunggang ing mattahastî, Z. H. Yudhisthira vormde haar geleide rijdende op een bronstigen olifant, BY. 9, 9. S a hongkârâng lrâkĕn kusuma, met het uiten van (de heilige lettergreep) ôm! bloemen uitstrooiende, 20,5. Kunang Bhaṭâra Guru tumulusakĕn agawe raṇu, en Bhațâra Gugu ging voort met vijvers te maken, Kosm.; tulusakĕna tang prang adbhuta, moge de vervaarlijke oorlog ten einde toe voortgezet, tot een goed einde gebracht worden, BY. 23,18 ; tulusakĕna tikung prih, ga voort met dien uwen ijver (ernstig streven), AW. 69 ; manulusakĕna, om te bestendigen, Âdip. 86 . Sakweh ning panah indrajâla kinĕnâken ira, allerlei tooverwapens werden door hem gebruikt om doel te treffen, d. i. werden aangewend, BY. 4:2, 7. K ĕ m bang wîja niwedya lot di inawuhakĕn irângalpika, bloemen en korrels als offerhande werden zonder ophouden door hen neergestrooid, terwijl zij vrome hulde bewezen, 22, 7. Ngkâneng waṇḍira yan kinaryyakĕn i Kurupati ri pakon irâtuta, daar bij den Waringin, liet de Kuruvorst hem (Bhîșma) liggen, toen deze hem vermaande vrede te sluiten (met de Pạndawa's), 13, 11. Nâhan teki nimitta ni nghulun angaryyakĕn ri sang arûm, dit nu was de reden waarom ik de aanminnige verliet, BY. 44.

Uit eenige der hier aangehaalde voorbeelden kan men zien, hoe werkwoorden op akĕn, schoon ze transitief ziju, zoo als duidelijk blijkt uit het passief, toch gevolgd kunnen worden door een voorzetsel dat den datief aanduidt. De reden hiervan is dat in de taal de neiging bestaat een accusatief te vervangen door een datief. Trouwens ook in andere talen komt hetzelfde voor, o. a. in 't Spaansch, Hindustânî, Gruzisch, al is 't gebruik beperkt tot bepaalde gevallen. Ook in onze taal vertoont zich hetzelfde verschijnsel, doch in zeer geringe mate, namelijk bij de voornaamwoorden hem, haar, hun of hen, allen eigenlijk datieven.

Aanm. Met Ojav. a k ĕn komt in vorm en beteekenis overeen in Krama akĕn der hedendaagsche taal, als ook de kortere vorm $\mathrm{k}$ ĕn in gedichten; voorts kön in 't Sund., kon Lampongseh, Dairisch Bataksch kĕn, Tobasch kon (spr. hon), Maleisch kan. 
In de meeste talen van den Indischen Archipel ontbreekt de formatie met akĕn, enz. en wordt dezelfde functie vervuld hetzij door voorvoegsel i, gelijk in de Filippijnsche en zich daarbij aansluitende talen, of wel door 't achtervoegsel ang, zooals in t Makassaarsch en Balisch. Aangezien in de meeste talen der Stille Zuidzee de suffixen aka(n) en aki of ake en in 't Mafoorsch e pĕn (uit akĕn) in hoofdzaak dezelfde beteekenis hebben als a kĕn, kön, enz., moet men aannemen dat dezelfde formatie reeds in de grondtaal bestaan heeft. Dat a k ĕn, kan en aki, ake eigenlijk synonieme partikels zijn en 't Njav. Ngoko ake beantwoordt aan 't aki, ake der talen van de Stille Zuidzee, vindt men elders aangetoond, alsook dat het Ngadju-Dajaksch děngan (= Mal.) bezigt met in veel gevallen dezelfde functie ${ }^{1}$. Ten opzichte van 't Ngoko ake, Lampongsch ki, mag hier echter niet verzwegen worden dat volgens de meening van wijlen Dr. van der Tuuk, 't aanhechtsel ake vroeger niet bestaan kan hebben, omdat de uitgang van den conjunctief a k ĕna, ĕna is ${ }^{2}$; doch een overgang van a k ĕn in a ke is volstrekt in strijd met alle regelen van klankontwikkeling. Ware ake de Kramavorm. dan zou men nog kunnen denken aan een willekeurige, opzettelijke verandering, maar ake is juist de Ngokovorm. Dit gevoegd bij 't feit dat in zooveel verwante talen a kan en a ki, a ke of de kortere vormen er van als synoniemen optreden, leidt tot de slotsom dat de meening van v. d. Tuuk onaannemelijk is. Veeleer mag men onderstellen dat a ke oudtijds slechts gewestelijk voorkwam - het is trouwens nog niet algemeen, want in 't Bantamsch Javaansch is alleen a kĕn in gebruik - en dat het later ingang heeft gevonden in het heerschende dialekt, hetwelk den grondslag vormt van 't Oudjavaansch, doch het is niet bij machte geweest den conjunctiefvorm van 't heerschend dialect te verdringen, hoezeer deze een eigenaardige, schoon verklaarbare verkorting in bepaalde gevallen ondergaan heeft.

Wijzen en tijden van 't werkwoord.

Men kan in 't Ojav. drie Wijzen onderscheiden: Indicatief, Conjunctief en Imperatief, actief en passief. Een Infinitief bezit de taal niet; wel heeft ze verbaal-substantieven, bijv. paturu, wijze

1 Zie „De Fidjitaal", blz. 84.

${ }^{2}$ K. B. Wdb. I, 138. 
van slapen, 't slapen: pating ga l, 't verscheiden, overleden zijn ; paninggal, verlating, afscheidneming, e. dgl. en deze verbaalsubstantieven moeten in onze taal menigmaal met den zgn. onafhankelijken infinitief vertaald worden, maar deze laatste is geheel en al een substantief, wordt verbogen en regeert deuzelfden naamval als 't substantief, zoodat het niet bij 't werkwoord behoort. Oorspronkelijk is zelfs onze werkwoordelijke af hankelijke infinitief een substantief en wel een verbogen substantief. Onze afhankelijke infinitief wordt in t Ojav. vervangen door den conjunctief, evenals bijv. ook in 't Nieuw Grieksch.

Van de Tijden is op te merken dat er geen vormelijk onderscheid gemaakt wordt tusschen tegenwoordig en eenvoudig verleden, behalve dat de vorm met voorvoegsel $\mathrm{ka}$ een toestand aanduidt ten gevolge van een voorafgaande genoemde handeling en in zooverre iets verledens te kennen geeft. Als men in 't oog houdt dat de Ojav. werkwoordsvormen te vergelijken zijn met onze deelwoorden, dan zal men 't gemis van een onderscheid tusschen tegenwoordig en eenvoudig verleden niets vreemds vinden, want in ons tegenwoordig deelwoord ontbreekt het onderscheid evenzeer; bijv. "dit ziende ging hij weg" is "toen hij zag ging hij weg." Met het onderscheid tusschen tegenwoordig en eenvoudig verleden, verwarre men niet dat van perfectief en imperfectief, welk onderscheid in 't Ojav. wel wordt uitgedrukt, zooals men gezien heeft. Dit is een verschil van handelingswijze, niet van tijd.

Eene imperfectieve handeling welke in 't verleden verplaatst wordt, hetgeen wij plegen uit te drukken door den VolmaaktVerleden Tijd of het Plusquamperfectum, kan in 't Ojav. aangeduid worden door een imperfectief voorafgegaan door huw us, sămpun, tĕlas, hénti, waarin 't begrip ligt van "afgedaan, bereids, reeds", doch meestal is de beteekenis dezer woorden nog zóó duidelijk dat men ze niet onvertaald kan laten, terwijl ze in 't Nieuwjav. hun zelfstandigheid verloren hebben. Bijv. tucapa Kurunâtha, mijil ri yawa, sâmpun açoca mabhûșaṇa, laten wij spreken van den vorst der Kuru's, hij trad naar buiten, na zich gewasschen en uitgedost te hebben, BY. 4, 8. Ikâng a mbĕk yan sâmpun amageh anût ring brata tapa, wanneer de geest al (of: eenmaal) standvastig de zelfkastijding nakomt, AW. 57. Milwa mati lad ramangku sâmpun hilang, om in den dood mijn vader te volgen die reeds gestorven is, BY. 50, 19. Tan warṇnanĕn sira huwus tĕka ring 
swaw eçma, we zullen niet beschrijven (wat hị deed), toen hij reeds tehuis gekomen was (nadat hij tehuis gekomen was). Tĕlas a pagĕh gĕlar uira, zijn slagorde was reeds (reeds volledig) vastgesteld, 25, 6. A pan iki milwa ri sang tĕlas paratra, want zij zou nu den reeds overledene volgen, 14, 5. W w ang sânak hĕnti kâprĕm, mijn broeders reeds gesneuveld, 50, J9. ${ }^{1}$ Intusschen blijkt uit dit laatste voorbeeld, dat men in onze taal volstaan zou kunnen met "den overledene", zonder "reeds". En zoo ook menigmaal elders; bijv. wanneer aan 't einde van een document gezegd wordt "tĕlas sinurat", dan is dit eenvoudig te vertalen met "geschreven", maar altijd ligt daarin de beteekenis dat iets tengevolge van een opzettelijke handeling "af " "voltooid" is.

Het Futurum en de Conditionalis worden steeds duidelijk van den tegenwoordigen en verleden Tijd onderscheiden, en wel door den vorm die ook voor den Conjunctief dient. Ook in ettelijke Indogermaansche talen wordt het Futurum door een Conjunctief uitgedrukt.

Over den Imperatief is reeds bij de behandeling der wkw. vormen met voor- en achtervoegsels 't noodige gezegd ${ }^{2}$. De vetatief wordt uitgedrukt door haywa, zeldzamer door haja, gevolgd door den imperfectiefvorm van den indicatief actief. H aja schijnt grover dan ha $y w a$; het is, zooals bekend, het thans gebruikelijk woord in Ngoko, en is overoud, want het komt overeen met het Malagasi a $\mathrm{z}$, dat dezelfde functie heeft.

\section{H. KERN.}

\footnotetext{
' Identisch met hĕnti is Fidji oti, Eromanga oti, Mota, enz. ti, dat dezelfde functie heeft.

2 Vgl. ook "Eenige imperatiefvormen van het Oudjavaansch" in deze Bijdragen 5, IV, 10-43.
} 